\title{
NOTAS PARA UMA ABORDAGEM DO DISCURSO DE SALA DE AULA: UMA LEITURA EM CONTRAPONTO
}

\section{Maria Ester Vieira de Sousa (UFPB)}

Neste artigo, a partir da descrição de situações típicas do discurso de sala de aula, buscarei delinear uma perspectiva metodológica de análise desse discurso, com base nos pressupostos teóricos da AD, estabelecendo, explícita ou implicitamente, um breve contraponto com outras abordagens. Para tanto, utilizarei dois exemplos, retirados de corpus gravado (em áudio) em duas salas de aula de $5^{\text {a }}$ do ensino fundamental, cada um pertencente a uma escola diferente. Passemos imediatamente ao primeiro exemplo:

LIP, I: o quinto (+) ((a professora passa a ler o enunciado da questão proposta pelo LD)) copie em seu caderno (+) o significado da palavra em negrito nas fiases seguintes de acordo com a página de dicionário dal da página ao lado $(++)$ o professor ficou...

\subsection{1: $\quad$ [encuntado}

Lo.1: $\quad$ /seduzido

L7A: Lseduzido seduzido(+) [elevado

LSP: To que é encantado?

L9Axx: seduzido

L10A: elevado (+) professora

L11A: contente

L12.4: contente

O LD utilizado nessa escola, à época da pesquisa (1999), era Soares (1990). A atividade, objeto de discussão, encontra-se à página 5 do referido livro. $\mathrm{Na}$ legenda utilizada para a transcrição, $\mathrm{P}_{1}$ corresponde à professora do primeiro recorte, $\mathrm{P}_{2}$, à do segundo; $\mathrm{A}$, ao aluno, $\mathrm{Axx}$, a vários alunos falando simultaneamente e L1, L2 ... correspondem às linhas do recorte, para facilitar a referência durante a análise. A pausa foi marcada por $(+)$; as falas sobrepostas pelo [ e o alongamento de vogais por :: 
L13P: contente com as redações do alu:nos

L14A: onde foi que tu encontrasse?

L15A: olhe aqui

L16A: satisfeito

L17A: eu botei assim(+) muito contente (+) satisfeitissimo

LI8P: Ou um ou outro

L19A: (incompreensivel) ((Barulho))

L2OP: a letra b (+) ele mora muma casa encantadora...

L21A: [mágica (+) maravilhosa (+) encantadora (lVarios alunos dão outras respostas, mas não é possivel recuperar))

L.23P: fascinante né? Maravilho: :sa

L24A: distraida

L25A: eu botei fascinante $(+)$ maravilhosa

L26A: distrai:da (+) professora

L27A: Aletrac (+) perai

L28P: Victor (+) como é casa distraida? diga ai pra mim (+) como é essa casa?

L.29A: errei (+) errei

L30P: tá (+) tem que saber o que tá colocando la $(++)$ a letrac $(+)$ contratei um jardineiro para encanteirar o jardim...

L32Axx: contratei um jardineiro para por canteiros

L33A: contratou um jardineiro para plantar em canteiros

L34A: por canteiro?

L35P: por canteiros (+) não é? letra d(+) domingo eu vou encanteirar mudas de roseira em meu quintal...

L37Axx: [plantar mudas (incompreensivel)

L381: $\quad$ plantar en canteiros

L39P: plantar em canteiro (++) letra e $(+)$ a feiticeira tenton encantar o principe...

L41A: lançar encantamento ou mágica so/sobre

L42A: $\quad$ lançar encantamento

L43A: [en/enfeitiçar

L44A: [seduzir cativar maravilhar arrebatar

L45A: [transformar pessoa em outro ser

L46A: Flançar encantamento (1O barulho aumenta: vários alunos respondem ao mesmo tempo)) 
L.4SP: Lum de cada vez (+) olha a feira (+) olha a feira (+) fala Marco (+) so Marco (+) fala Marco (+) olha o nome que eu estou fallando Mar:.:co

1.51).1: Lança énceantamento) ou mágica sobre (+) na historria da Bela adormecida la feiticeira encantou a princesa

L.52P: Lauem quem fé diferente levante o bra:ço

L5.3.1: eu $(+)$ que faz encantamento $(+)$ mágica

L.5HP: ou um ou outro /ou mágica ou que faz encantamento)

L.55.1: [cativa seduz

1.56P: fera diferente (+) Caio fala

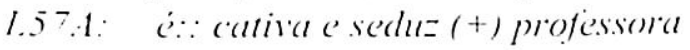

l.5sP: is Ana agora (+) fiala

1.59.1: (incompreensivel) (t.1 aluna fala muito baivo))

Lorin): quem fez diferente. Fale

1.61.1: lançar encantamento ou mágica sobre (+) enfétiçar

1.62P: fala

L.63.1: en botei cativa seduz

l.otl?: para ew fale

1.05.1: para encantar Branca de Neve (t) a rainha

(incompréensivel) (V'arios alunos falam simulaneamente))

lisse recorte revela, sem dúvida, uma situação-simbolo da sala de aula: a professora desenvolve com os alunos a correção de uma atividade proposta pelo I.I). Do ponto de vista superestrutural ${ }^{2}$ o discurso também revela uma organização típica da sala de aula: a

lissa estrutura das interaçòes em sala de aula. baseada no esquema inciaçào-resposta-avalaç̣ào, é objeto de estudo de varras pesquisas, dentre (las. Itrickson (1982), Kramsch (1984). Van Lier (1988). Cazden (1988). Ao lado dessa estrutura tipica. outras formas de organização da interaçào cm sala de aula também têm sido ressaltadas. Para Erickson (1982), por excmplo, a aula seria determinada por principios de organizaçào local e não local, colocando-se como un meio termo entre a formalizaçào de rituais preestabelecidos e a espontaneidade de um contexto mais livre. No Brasil. principalmente na década de 90 , cresce o número de trabalhos sobre essa questão, dentre os quais citamos Bortoni e Lopes (1991). Smolka (1991a,1991b), Coracini (1994, 1995). Embora essas pesquisas revelem perspectivas teóricas distintas, o que implica um ollhar diferente sobre a sala de aula, todas partem do pressuposto de que o funcionamento das interaçòes tem um papel signification na aquisiçào do conhecimento. 
professora inicia a interlocução, controla e distribui a palavra entre os alunos, avalia o que eles dizem. Mudam as estratégias locais, mas o esquema geral se mantém: a professora sempre inicia um movimento interlocutivo lendo uma questão do LD; em seguida, os alunos respondem e, por último, ela avalia, positivamente, repetindo a resposta considerada correta. A partir de certo momento da aula, transcrito à linha 48, ela muda as estratégias de controle da palavra e de avaliação: como se instaura uma certa confusão, com vários alunos falando ao mesmo tempo, a professora passa a indicar/nomear o próximo falante e, como ela se cala sobre a resposta dada, supõe-se que o silêncio passa a funcionar como um consentimento às respostas dadas pelos alunos ("quem cala consente"). Provavelmente, a ausência de uma avaliação explícita também seja resultante da necessidade de controlar o barulho. Ao imprimir um ritmo mais acelerado à correção da atividade, ela parece querer exigir maior atenção dos alunos e, naturalmente, o fim do barulho.

Como era de se esperar, essa organização discursiva em que o professor é o responsável pelo controle da fala é comum nas duas escolas em que as aulas foram gravadas, conforme podemos notar nesse outro recorte retirado de outra aula:

(2)

$\mathrm{LIP}_{2}$ : olhem (+) prestem atenção (+) fizemos o te: $\mathrm{xto}(+)$ fizemos a nossa pequena avaliaçã̃o (+) certo?" eu quero depois ollhar (+) éh olhar direitinho (+) quando eu ler as redaçóes de vocês (+) ai a gente vai discutir melhor (+) certo? Agora eu quero que vocês observem (+) da mesma forma que a gente observou a tela de Di Cavalcanti (+) eu vou pedir pra vocês que observem essa fotografia (+) (A professora mostra aos alunos uma fotografia da Revista IstoE)

L8A: O::h! (tom irônico)

L9A: U:au

L10A: deixa eu ver!

L11A: deixa eu ver!

L12A: deixa eu ver (+) professora

L13A: uma mulher operando ((P mostra a fotografia a cada aluno))

L14P: a fotografia (+) da mesma forma que (+) uma te:la (+) por exemplo (+) figurativa né? (incompreensivel) éh eia musua imagens né? ela mostra imagens e: mostra alguns elementos 
(+) claro né? mostra imagens (+) essas imagens contém elementos(+) da mesma forma que a gente observou os elementos na te:la (+) a gente vai observar esses elementos dessa fotografia aqui (+) por exemplo (+) que ambiente (inaudivel) ((Conversas paralelas))

L21Ax: (incompreensivel)

L22A: hospital

L23A: uma sala de cirurgia

L24A: cirurgi:a

L25P: através do que vocês éh quais os elementos que comprovam (+) que elementos comprovam que se trata de uma sala de cirurgia?'

L27.4x: os aparelhos ((muitos falan! ao mesmo tempo e há muito barulho))

L28A: os equipamentos

L29P: os aparelhos (+) e o que mais?

L30A: $\quad$ Cas máscaras

L31A: [a cobaia

L32P: a máscara das pessoas (+) significa que se trata de médicos

L33A: o sangue!

L34P: o sangue...

L35.4: a cobaia!

L.36.A: (incudivel)

L37.4: não é não, uma cobaia?

L3SP: o paciente?

L.39.4xx: É ! É

L.40P: éh vocês imaginam que essas pessoas possam estar passando (+) por um momento dificil da cirurgia?

L42Ax: si::m

L43A: não! nã :*o!

L44P: através/ por que não?

L45A: porque estão tão contentes ou talvez (incompreensivel)

L46Axx: a: h ((Vários alunos falam ao mesmo tempo. Há muito barulho.))

L47P: olha (+) a maioria respondeu que sim certo? então vamos/ eu quero que vocês respondam que elementos comprovam que elas estão passando por um momento dificil na cirurgia

L50A: é porque na operação tudo funciona assim (incompreensivel) 


\section{L5l.1x: (incompreensivel)}

L.5.2P: a expressão das/ das pessonas (+) nào é isson" a expresisão das pessoas (+) certo." entäo é o seguinte (+) a gente imagina também que eles/ que essas pessonas estariam comersando nesse momento ((Barulho)) discutindo alguma coisa (t) discutindo o problema (t) näo $e^{\prime}$ (incompreensivel) estariam conversundo (t) entào a gente vai fazer o se'guinte $(+)$ da mesma forma da mesma forma yue voces produziram

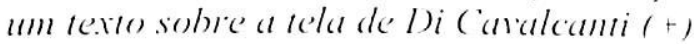

L.59:1: A::i!

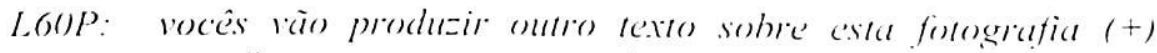

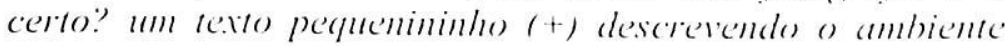

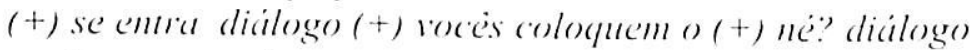

L.63.1: professora + +) épra casa ou pra agora.'

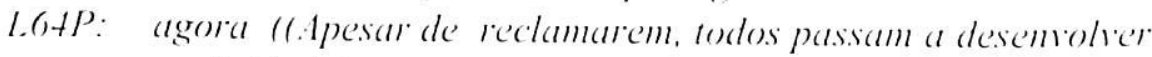
(atividade))

Nos dois recortes, a relação professor/aluno ocorre em função de uma atividade: no primeiro. mediada diretamente pelo L.D. no segundo, por uma fotogralia de uma revista. Assinalemos. entretanto. que, no segundo caso, o LD, mesmo indiretamente, também está mediando a relaçào: a professora inicia a atividade fazendo referência a uma outra atividade que havia sido desenvolvida a partir do I.D e ela solicita que os alunos façam "da mesma forma". Nas duas aulas, além de predominar o mesmo esquema geral de organização discursiva, as professoras usam uma mesma estratégia de araliação das respostas dos alunos, ou seja, ambas recuperam uma das respostas tida como correta. Também surgem formas de ações lingüisticas que são peculiares à escola, como as questóes didaticas., as quais ora

Alguns autores consideram as questóes diditicas como um subtipo do questionamento em que ocorre uma subversào do caráter usual da peregunta. ou seja. o professor pergunta, mas nào descja informar-se acerca do conteúdo real da pergunta, pois já sabe a resposta. Por se tratar de $u$ m recurso bastante comum na sala de aula, vários trabalhos - dentre os quas (jabhiani (1901) tem se dedicado à sua analise, destacando as suas implicaçòes pedagógicas. Batista (1997:39 e segs.) também ressalta que a organizaçào local da interlocuçào em sala de aula tende a segur esse esquema de sequiencias triadicas. Contudo. Batista (1997) aprofunda mais a discussão acerca dessa estratégia discursiva como o resultado das condições de produção desse discurso. 
luncionam como uma forma de monitoramento do conhecimento, ora como uma forma de controle da atenção do aluno.

Contudo, essas constatações dizem muito pouco da prática discursiva em sala de aula enquanto um acontecimento discursivo. Em principio, essa estrutura geral de organização do discurso nos diz apenas que o professor está exercendo uma de suas funçōes naturalizadas - a de controlador da aprendizagem - e, ainda assim, diz. muito pouco do exercicio dessa função.

Un enunciado deve. no mínmono. ser considerado em sua relação com um outro que o antecede ou o segue. Como alirma Bakhtin (1986:113): "A palavra é uma espécie de ponte lançada entre mim é os outros. Se ela se apóia sobre mim numa extremidade. na outra. apoiase sobre o meu interlocutor." Entre a minha palavra e a do meu interlocutor não há apenas acordos firmados, existem também enfientamentos, desavenças, desacordos. Nem por isso elas deixam de se encadear, de "ter relação", quer seja de prolongamento, de réplica ou atli mesmo de desapreço ou desconsideração. Fundamentalmente. como sugerem François (1993) e (unha (1992), bašados em Bakthin. um enunciado pode "ter relação" com outro(s), mesmo quando introduz em relação àquele(s) un deslocamento ou um movimento inesperado.

Segundo François (1993:116), o encadeamento discursivo se realiza por diferentes modos, podendo haver ou não um organizador sintático - como os conectivos, os processos de lexicalizaçào etc. que o explicite. Dentre as modalidades discursivas. François (1993) refere-se ao modo paralelo, caracterizado pela presença de enunciados em série que mudam o conteúdo, mas mantêm a mesma forma e o mesmo gênero; ao modo complementar. baseado fundamentalmente no esquema questão-resposta: e ao modo do comentúrio. marcado pela retomada, pela modificação do discurso do outro.

lissas modalidades de encadeamento também possibilitam apresentar uma visão genérica dos recortes anteriormente citados. Primeiro, predomina, principalmente no recorte (1). o modo complementar de enunciação, ressaltando-se o típico da sala de aula, ou seja, o enunciado gerador é sempre da professora que formula uma questão à qual os alunos respondem. Ocorre que os enunciados das professoras funcionam nào apenas como geradores, mas também como reguladores e reagrupadores do discurso dos alunos, na medida em que cla comenta, modifica, sintetiza o que eles dizem. Nesse sentido. o 
discurso do professor, ao estabelecer sínteses e reformulações, torna-se também excludente e redutor, na medida em que várias respostas dos alunos deixam de ser contempladas. Esse aspecto não revela uma falha da professora, mas uma falta do sujeito, que não é onipotente. Ou seja, as reformulações, as sínteses não podem fugir de sua condição de excludentes e redutoras, o que varia, e que é também condição do sujeito, é o modo e grau de exclusão ou redução.

O modo paralelo também pode ser considerado como característico do discurso de sala de aula: os enunciados dos alunos tendem a se apresentar como séries paralelas entre si que, enquanto tal, naturalmente estão juntos, mas não se cruzam, não se articulam no nivel intradiscursivo. Ou seja, quando o foco da relação é o conteúdo de ensino, o aluno dificilmente encadeia o seu enunciado sobre o de outro aluno, a tendência é que esse enunciado se articule diretamente ao da professora ${ }^{+}$. Isso não significa, entretanto, que, num nível interdiscursivo, os enunciados dos alunos não possam estabelecer relações. Esse aspecto demonstra que, na perspectiva da materialidade lingüística, não podemos nos limitar apenas à análise de elementos lingüísticos explícitos que, em princípio, servem para ligar uma fala a outra - como a repetição, a retomada, através de anáforas, de sinônimos etc. É preciso ressaltar que a relação entre enunciados, tal qual aqui considerada, nem sempre supõe a existência de formas ou marcas lingüísticas explícitas. Além disso, essas marcas, quando existem, devem ser contempladas em função das suas condições de produção, uma vez que, por si só, não são suficientes para compreender o funcionamento discursivo.

Explicitamente, esses recortes, ao lado das semelhanças, também revelam diferenças. As professoras, por exemplo, usam estratégias discursivas diferentes para iniciar a interlocução; para a avaliação das respostas dos alunos, as estratégias se assemelham, contudo não possuem um mesmo funcionamento; os alunos, por sua vez, não têm o mesmo comportamento na relação con a professora. Notemos que $\mathrm{P}_{1}$, talvez devido à natureza da atividade, extremamente centrada no LD, é mais direta, mais objetiva. Ou seja, ao iniciar a interlocução, ela se limita à leitura das questões do LD que passam a

Quando se trata de conversas paralelas, em que dificilmente o tema é o conteúdo de ensino, naturalmente essa tendência ao modo paralelo de encadeamento é anulada. 
funcionar como a questão/pergunta a ser resolvida/respondida pelos alunos. Já $\mathrm{P}_{2}$, na maioria das vezes, inicia um movimento recuperando um conteúdo anterior relacionado com o que a seguir será trabalhado. $\mathrm{Na}$ sua primeira intervenção, quando pede para que os alunos observem a fotografia, $\mathrm{P}_{2}$ parece pretender treinar/cutomatizar um procedimento de leitura do texto não-verbal que antes já havia sido iniciado. Esse objetivo torna-se claro na sua segunda intervenção, cuja transcrição tem início na linha 14 . Trata-se de mecanismos distintos que, certamente, possuem um funcionamento diferente.

$O$ recurso lingüístico utilizado para a avaliação, ao lado das semelhanças, também revela diferenças: enquanto $P_{1}$ repete a resposta considerada correta ou silencia sobre as respostas apresentadas, fazendo supor que elas foram aceitas, $\mathrm{P}_{2}$ ora repete a resposta - como, na linha 29, quando repete "aparelhos", recuperando a resposta antes apresentada por vários alunos - ora reformula/amplia uma das respostas, acrescenta-lhe um comentário - como ocorre na linha 32.

Quanto ao comportamento dos alunos, embora nas duas aulas haja uma participação significativa, numa aula eles parecem mais "obedientes", na outra, o barulho constante parece indicar que os alunos são mais resistentes ao tipo de interação típico da sala de aula. Esse aspecto está, sem dúvida, diretamente relacionado à posição que professor e aluno ocupam no discurso. Vejamos que a primeira professora $\left(\mathrm{P}_{1}\right)$ (re)constrói de forma mais marcante o papel social de professor controlador da disciplina e de organizador da atividade discursiva - ela reclama do barulho ("olha a feira, olha a feira"), controla e indica o próximo interlocutor ("olha o nome que estou falando". "é Anc agora". "fala"). Na outra aula, parece existir um abrandamento por parte da professora $\left(\mathrm{P}_{2}\right)$ em relação às normas disciplinares da escola. Ou seja, elas se posicionam de forma diferente na sua relação com os alunos.

Ocorre que as diferenças não surgem apenas do confronto entre as duas aulas, elas se revelam numa mesma aula. Afirmei anteriormente que o recorte (1) é, em princípio, extremamente marcado pelo controle da professora. Entretanto, esse controle não é total. A título de exemplo, sugiro ao leitor voltar ao trecho inicial daquele recorte.

Nesse trecho, a frase a ser trabalhada era "O professor ficou encantado com as redaçós dos alunos" (Soares, 1990:5) e os alunos deveriam apresentar o significado - conforme enunciado da questão 
lido pela professora em L1P - para a palavra destacada. A professora suspende a leitura da frase exatamente onde aparece a palavra que deverá ser substituida. Em L5A, o aluno simplesmente repete a palavra que está dada na frase, provavelmente completando a leitura interrompida pela professora. As respostas começam a ser apresentadas ora simultaneamente, como em L6 e L7 e depois repetida $\mathrm{em} \mathrm{L9} \mathrm{por} \mathrm{vários} \mathrm{alunos;} \mathrm{ora} \mathrm{em} \mathrm{seqüencia,} \mathrm{como} \mathrm{das} \mathrm{linhas} 10$ a 12 . Ressalte-se que os alunos apresentam respostas diferentes: três significados (para seguir a orientação do enunciado da questão) são apresentados: seduzido. elevado é contente.

A professora - que, cm princípio, controla tudo - elege contente como a resposta correta, tanto que conclui, em L13, a sua frase. iniciada e suspensa em L.4, utilizando essa resposta. Do ponto de vista discursivo, o enunciado da professora - no momento cm que é suspenso e. portanto, não se completa - cria uma fissura na linearidade da frase que passa a ser preenchida por todas as respostas apresentadas pelos alunos, as quais estão numa relação de complementaridade com esse enunciado interrompido. Quando a professora, em L13, volta a encadear o seu enunciado, fechando/costurando a abertura, deixa de fora os outros sentidos apresentados pelos alunos. Nesse caso, parece que o provérbio "quem cala consente", a que anteriormente me referi, já não pode ser aplicado, dado que una resposta foi alçada à condição de correta. Isso revela que, apesar de a professora impor uma resposta, não controla todos os sentidos apresentados. Esse é um aspecto bastante significativo para qualquer análise do discurso de sala de aula: o que escapa ao controle do professor.

As constatações, até agora assinaladas, permitem afirmar uma noção básica para a $\mathrm{AD}$ : a linguagem é atividade, é lugar de constituição dos sujeitos que não são oniscientes, nem onipresentes. E aqui uma outra constatação óbvia: como todo sujeito, professores e alunos constituem-se na sua relação um com outro e com os outros ${ }^{5}$.

Ao dizer que os sujeitos (professores e alunos) são constituídos, não estou afirmando que eles sào totalmente determinados, mas, antes, ressaltando que, na relaçào com o outro, eles também criam relações de poder (Foucault, 1979:1987). Essa questão não será aqui aprofundada, mas relembro que as relaçōes de poder. ao mesmo tempo que assujeitam ou reprimem, criam/possibilitam resistências. 
Penso essa alteridade na perspectiva do sujeito e do discurso, ou seja. não ha um sujeito, aluno ou proféssor, pronto, imune às influências do outro durante o processo interlocutivo; também não existe um sujeito. aluno ou professor, que esteja começando de um ponto zero. já que existe um passado discursivo que constitui, delimita e legitima o lugar de professor e de aluno. Ou seja. mesmo quem ainda não foi à escola possui um saber. uma memória discursiva (Pêcheux, 1997), sobre a éscola, sobre o que é ser aluno e o que é ser professor.

Entretanto, o ser aluno e o ser professor nào correspondem. total ou necessariamente, a esse saber preconcebido, já que a relação dos sujeitos supõe muito mais do que a simples atualização de um padrào de comportamento e de discurso. É comum, por exemplo. na sala de aula, momentos em que os alunos conversam (conversas paralelas), brincam. Em uma das escolas, inclusive. freqüentemente, cles cantam. fazem piadas com os colegas. Essas ocorrências podem perficitamente ser consideradas como formas explícitas de resistencia dos alunos aos padròes de comportamento exigidos pela escola. Há lambèm formas mais sutis de resistência - que atuam tanto em relaçào a esses padrōes quanto em relação ao conteúdo de ensino.

Todas essas questões nada mais revelam que uma concepção dinâmica de linguagem que visa contemplar o seu caráter histórico: "Mistórico como um processo que, reassumindo embora o material e as direçós escolhidas do passado, recompõe aquele e reorienta estas. Näo é um. recomeçar: como não é um repetir" (Franchi, 1992:29). Ademais, revela que o sujeito não é onipotente e, por isso mesmo. nem é a fonte única do sentido nem prescinde da relação com o(s) outro(s).

Por um lado, se na linguagem nunca temos um eterno repetirse. os mecanismos lingüísticos, sintáticos e semânticos, atualizados no discurso não poderão ser considerados únicos nem possuindo uma significação aprioristica. Essa indeterminação sintática e semântica, de que falam Franchi (1992) e Possenti (1993), permite compreender os mecanismos lingüísticos em sua emergência, na instància que produz. o discurso, enquanto acontecimento. Por outro lado, se na linguagem nunca estamos começando, é porque os recursos lingüísticos constroem a sua história que fala do seu uso e do seu funcionamento.

A título de exemplo, podemos notar que o recurso lingüistico da repetição, presente nos recortes anteriormente citados, possui 
funcionamentos que revelam uma história de uso da linguagem em sala de aula: ora servia para que as professoras avaliassem como correta a resposta do aluno, ora se mostrava eficaz enquanto estratégia de recuperação de um conteúdo anteriormente trabalhado em sala de aula, ou seja, enquanto técnica de memorização/automatização do conhecimento. Isso também demonstra, como afirma Possenti (1993:114), que, se os recursos lingüísticos não são suficientes para a interpretação, também não podem ser desprezados.

Concluindo, estou sugerindo, enquanto procedimento, a análise do encadeamentos (da relação discursiva) entre os enunciados de professor e alunos - considerando as suas condições de produção nas quais se incluem os discursos-outros (da escola, do LD) sobre o mesmo objeto (conteúdo de ensino, relação professor/aluno) e o lugar e o papel sociais que os sujeitos ocupam na relação.

Esse procedimento que tem como foco o funcionamento discursivo, aliado ao objetivo imediato da análise, por vezes pode obrigar o analista a recorrer a trechos longos, visto ser necessário acompanhar todo um movimento discursivo que, às vezes, inclui várias intervenções das professoras e dos alunos. Apesar das dificuldades que esses recortes poderão impor à leitura, eles se fazem necessários para que se possa perceber, no encadeamento discursivo, o papel que os sujeitos desempenham e o lugar que ocupam no discurso. Além disso, conforme demonstram os exemplos aqui utilizados e aprofundados em Sousa (2000), a questão do típico e do diferente na sala de aula não é, do ponto de vista do discurso, nem tão simples nem tão óbvia.

Trata-se, assim, de analisar a emergência do dizer na sua relação com outro(s) dizer(es) - explícitos ou recuperáveis a partir de suas condições de produção - buscando compreender os efeitos de sentido" que provocam essa emergência em tais condições. E essa

Entendo efeitos de sentido, conforme Possenti (1993), enquanto possibilidades de interpretação, direções interpretativas a que a materialidade lingüistica nos permite, na qualidade de intérprete, ascender. Não é demais repetir que isso só é possível porque "as linguas naturais são sintática e semanticamente indeterminadas, no sentido de que qualquer enunciado demanda, para sua interpretação efetiva, além dos elementos da sintaxe e da semântica, uma relação ao seu contexto de produção" (Possenti, 1993:14). 
emergência demonstra a existência não apenas de regularidades discursivas. Dessa forma, essas questões apontam para um trabalho de interpretação dos dados numa perspectiva intradiscursiva $\mathrm{e}$ interdiscursiva, capaz de responder ao discursivo de sala de aula como acontecimento discursivo. É preciso não perder de vista uma questão que já foi enunciada: todo discurso se instaura na atmosfera do "jádito", ou seja, todo discurso é sempre-já constituído por outros discursos, que já falaram sobre o mesmo objeto, com os quais mantém uma relação de aceitação ou de discordância (Bakhtin, 1981, 1986).

Em relação ao discurso de sala de aula, o discurso do professor, por exemplo. se revelava múltiplo não apenas porque ele contemplava o outro (o aluno), mas também porque esse discurso é o resultado do trabalho do passado no presente, é sempre-já constituído por outros discursos. E esses discursos-outros nos falam da perspectiva teórica do professor acerca do conteúdo de ensino; da concepção de ser professor e de ser aluno na visão do professor; da relação do professor com o LD etc.. O discurso do aluno, por sua vez, igualmente está longe de poder ser considerado homogêneo: ele é o resultado não apenas de fatores imediatos mas também de um passado discursivo que fala sobre a função-aluno. Enfim, a análise dos encadeamentos discursivos deverá dar conta, a um só tempo, das relações de forças e das relações de sentido no/do discurso de sala de aula. Questões que aqui são enunciadas, mas não aprofundadas. Do que foi dito, tudo a fazer.

\section{REFERENCIAS BIBLIOGRÁFICAS}

BAKHTIN, M. Marismo éfilosofia da linguagem. 3. ed. São Paulo: Hucitec, 1986.

BAKHTIN, M. A poética de Dostoievshy. Rio de Janeiro: ForenseUniversitária, 1981.

BAtista, A A. G. Aula de Português: discurso e saberes escolares. São Paulo: Martins Fontes, 1997.

BORTONI, S. M. e LOPES, I. A. A interação professor $x$ alunos $x$ texto didático. Trabalhos em Lingïistica Aplicada, Campinas, n.18, p. 39-60, jul./dez. 1991. 
CAZDEN, C. B. Classroom discourse. The language of teaching and learning. Portsmouth, NH: Heinemann, 1988.

CORACINI, M. J. R. F. O caráter persuasivo da aula de leitura. Trabalho em Lingüistica Aplicada, Campinas, n. 24, p. 65-78, 1994.

CORACINI, M. J. R. F. (org.). O jogo discursivo na aula de leitura. Campinas: Pontes, 1995

CUNHA, D. de A. da. Discours rapporté et circulation de la parole: contribution à une approche dialogique du discours d'autri. Peeters; Louvain-La-Neuve, 1992.

ERICKSON, F. Classroom discourse as improvisation: relationships between academic task structure and social participation structure in lessons. In: L. C. Wilkinson (ed.). Communicating in the classroom. NY: Academic Press, 1982.

FOUCAULT, M. Vigiar e punir: nascimento da prisão. Petrópolis: Vozes, 1987.

FOUCAULT, M. Microfisica do poder. Rio de Janeiro: Edições Graal, 1979.

FRANCHI, C. Linguagem - atividade constitutiva. Cadernos de Estudos Lingüísticos. Campinas, n. 22, p. 9-39, jan./jun. 1992.

FRANÇOIS, F. Prática do oral: diálogo, jogo e variações das figuras do sentido. Carapicuíba: Pró-fono, 1996.

GABBIANI, B . Estrategias de interacion en el aula: implicancias pedagogicas de la triada pregunta-respuesta-evaluacion. Trabalho em Lingüística Aplicada. Campinas, n. 18, p. 29-38, jul./dez. 1991.

KRAMSCH, C. Interactions langagières en classe de langue: l'etat de la recherche anglophone et germanophone. E.L.A, n. 55 (Interaction et enseignement/apprentissage), p. 57-67, 1984.

PÊCHEUX, M. O Discurso: estrutura ou acontecimento. Campinas: Pontes, 1997.

POSSENTI, Sírio. Discurso, estilo e subjetividade. São Paulo: Martins Fontes, 1993.

SMOLKA, A L. B. A prática discursiva na sala de aula: uma perspectiva teórica e um esboço de análise. CEDES, n. 18, p 15-28, $1991 \mathrm{a}$. 
SMOLKA, A L. B. Múltiplas vozes na sala de aula: aspectos da construção coletiva do conhecimento na escola. Trabalhos em Lingiüistica Aplicada, Campinas, n. 18, p. 15-28, jul./dez. 1991b.

SOARES, M. Português através de textos, 5. 3. ed. São Paulo: Moderna, 1990.

SOUSA, M. E. V. Discurso de sala de aula: as surpresas do previsível. Tese de Doutorado. UFPE, mar. 2000.

VAN LIER, L. The classroom and the language learner. Londres: Longman, 1988. 